\title{
RGO-ZnO Nanocomposit Material of Enhanced Absorbance for Solar Energy Conversion
}

\author{
P. S. Khare, Rishikesh Yadav, and Abhaya Swarup
}

\begin{abstract}
Graphene has been proposed as a promising two-dimensional nanomaterial with outstanding electronic, optical, thermal, and mechanical properties for many applications. In the present work a process of developing nanocomposite structures of graphene with zinc oxide for applications of graphene in organic photovoltaic (OPV) cells have been described. An alkaline reduced Graphene Oxide/ZnO nanocomposite (RGO/ZnO) films by various routs of dip coating chemical casting methods on a glass slide are synthesized. The characterization of these films indicates that there is strong bonding between RGO and $\mathrm{ZnO}$, which will give well structured and quite stable nanocomposite. Photoluminescence spectrum results in broad range of excitations. The casting routs and conditions play an important role in the nanostructure and the photoluminescence properties of resulting nanocomposite. The overall characterization suggests that the $\mathrm{RGO} / \mathrm{ZnO}$ nanocomposite is a promising nanomaterial for Solar cells having improved absorbance efficiency. It is concluded that $\mathrm{RGO}-\mathrm{ZnO}$ nanocomposite very likely to play a major role in Photovoltaic or solar cell.
\end{abstract}

Index Terms - Graphene oxide, photoluminescence, $\mathrm{ZnO}$, reduction.

\section{INTRODUCTION}

Graphene is Carbon material with a one-atom thick and two-dimensional conjugated honeycomb lattice structure increasingly attracting scientists for its special characteristics [1]-[3]. Graphene oxide is a chemically modified graphene which is an atomically thin sheet of graphite that has traditionally served as a precursor for graphene [4]. Graphene, a single sheet composed of sp 2 -hybridized carbon, has drawn great attention owing to its outstanding electronic, optical, thermal and mechanical properties. Due to its unique and superior optical and electronic properties, much attention is focused on its application in the field of OPV applications. Potential application of Graphene Oxide and its reduced forms have an extremely high surface area; because of this, these materials are under consideration for usage in organic photovoltaic (OPV) cells [5].

Reduced graphene oxide (RGO) contains a mixture of $\mathrm{sp}^{2}$ and $\mathrm{sp}^{3}$ hybridized carbon atoms [6]. RGO leads to creation of new $\mathrm{sp}^{2}$ clusters through removal of oxygen, which provide reduction path [6]. In particular, GO by reduction chemistry and relative fraction of the $s p^{2}$-hybridized domains

Manuscript received August 17, 2012; revised December 23, 2012.

P. S. Khare is with the Department of Physics, University Institute of Technology, Bhopal M.P., India (e-mail purnimaswarup@ hotmail.com).

Rishikesh Yadav is with the School of nanotechnology, Rajiv Gandhi Proudyogiki Vishwavidalaya, Bhopal, M.P., India. Energy. provides opportunities for tailoring its optoelectronic properties, manipulation of the size and shape.

These facts are the reason of attraction to consider Graphene Oxide for the design and synthesis of new materials, including donor, acceptor, and interface layer materials with superior properties. The present study is also one of such attempts in which we have reduced $\mathrm{GO} \& \mathrm{ZnO}$ in various conditions to obtain the new nanocomposite demonstrating improved absorbance efficiency and suitable properties for photovoltaic applications.

Graphene owing to the presence of oxygen-containing functional groups and water above and below the carbon have basal plane [6]. Recently Akbar Bagri ,Cecilia Mattevi Muge Acik, Yves J Chubal and Manish Chhowalla observed that RGO is disordered, consisting of holes within the basal plane due to the evolution of $\mathrm{CO}$ and $\mathrm{CO}_{2}$ in agreement with the microscopy observations [7]. They also found that residual oxygen $(\sim 7-8 \%)$ in fully reduced $\mathrm{GO}$ is a consequence of the formation of highly stable carbonyl and ether groups that cannot be removed without destroying the graphene basal plane.

However, relatively fewer research results related to graphene-oxide semiconductor (e.g., zinc oxide $(\mathrm{ZnO})$, zinc tin oxide (ZTO), indium gallium zinc oxide (IGZO), indium zinc oxide (IZO), and indium oxide) composites have been reported so far and people started to turn their attention towards these materials [8].

Here, we report near-UV- to -near IR photoluminescence (PL) from solution-processed of alkaline reduced graphene oxide ( $\mathrm{RGO} / \mathrm{ZnO}$ ) nanocomposite. The UV absorption and PL emission characteristics dependence on the reduction of $\mathrm{GO}$ indicates that it originates from the recombination of electron-hole $(\mathrm{e}-\mathrm{h})$ pairs, localized within small $\mathrm{sp}^{2}$ carbon clusters embedded within a $\mathrm{sp}^{3}$ matrix.

\section{EXPERIMENTAL SYNTHESIS}

\section{A. Preparation of Graphene Oxide $(G O)$}

Graphene oxide (GO) was prepared from natural graphite powder (325 mesh) as the starting material by Hummers-Hoffman method [9].

\section{B. Synthesis of ZnO Nanopartices}

Zinc oxide nanoparticles were synthesized by Drop Casting Chemical Rout method. In brief 0.719 gram of $\mathrm{ZnSO} 4.7 \mathrm{H} 2 \mathrm{O}(0.05 \mathrm{M})$ was dissolved in $50 \mathrm{ml}$ with deionized water, then $\mathrm{NaOH}(0.05 \mathrm{M})$ or $\mathrm{NH} 3$ solution was added drop wise to the vigorously stirred above solution to adjust $\mathrm{pH}$ to about 7 until white precipitate were formed. Mechanical stirring solution or ultrasonic waves was used for 
stirring solution. The precipitate were filtered and washed with deionized water. The wet powders were dried at about $400 \mathrm{C}$ in air oven and the dried solids were grounded in an agate mortar and calcined at $7000 \mathrm{C}$ for 3 hours.

\section{Preparation of $R G O / \mathrm{ZnO}$ Nanocomposite}

The RGO/ZnO nanocomposite was synthesized with different concentration of RGO such as $0.05 \mathrm{mg} / \mathrm{ml}$, $0.03 \mathrm{mg} / \mathrm{ml}, 0.01 \mathrm{mg} / \mathrm{ml}$ suspended in distilled water and $0.05 \mathrm{MZnO}$ per $\mathrm{ml}$ added in each solution respectively. Mechanical stirring solution or ultrasonic waves was used for stirring solution. The $\mathrm{pH}$ value of each solution adjusts by drop wise adding alkaline solution $(\mathrm{NaOH})$. Thin films of $\mathrm{RGO} / \mathrm{ZnO}$ nanocomposite were deposited by dip coating method on ultrasonic cleaned glass slide and glass slide was heated about $1500 \mathrm{C}$ in air.

\section{CHARACTERIZATION}

The UV absorption spectra and Photoluminescence characterization of $\mathrm{RGO} / \mathrm{ZnO}$ Nanocomposite was done to study the physical properties. The UV-Visible spectra of graphene oxide/ZnO thin film on glass substrate were measured on Perken Elmer UV-Vis spectrometers and shown in Fig. 1. The corresponding PL spectra of $\mathrm{RGO} / \mathrm{ZnO}$ films after each incremental $\mathrm{Ph}$ with drop-by-method with alkaline solution shown in Fig. 2. PL peak position of thin films were found to change with $\mathrm{pH}$ value.

\section{A. UV Absorption Spectra of RGO/ZnO Nanocomposite}
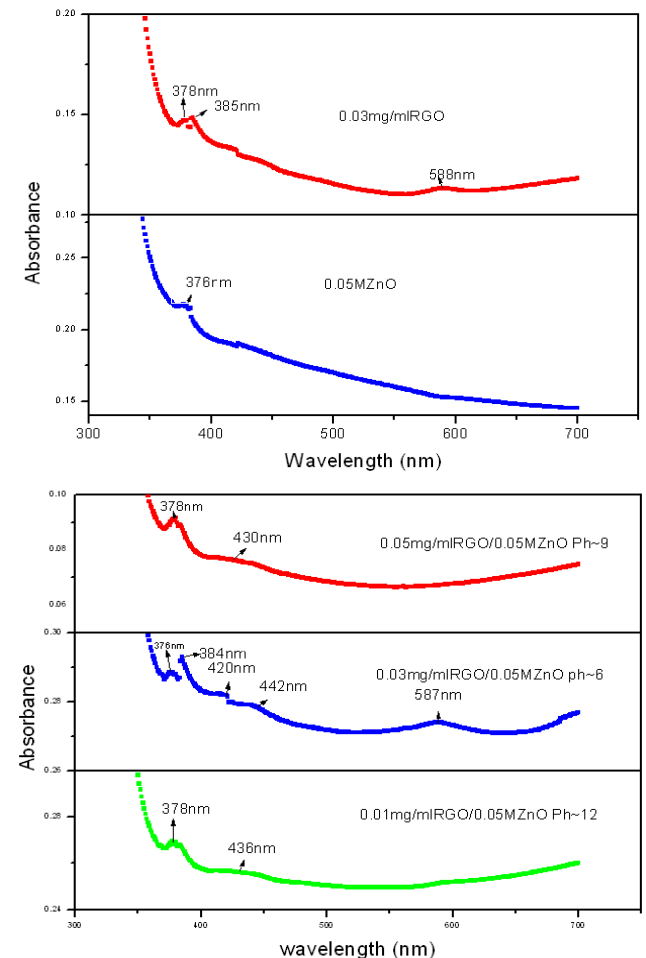

Fig. 1. UV absorption spectrum of $\mathrm{RGO}, \mathrm{ZnO}$ and $\mathrm{RGO} / \mathrm{ZnO}$ nanocomposite.

The absorption spectra of RGO sheet at $378,385 \mathrm{~nm}$ show centered peak. This indicates that there is strong binding between composite material. The main absorbance peak attributed to $\Pi-\Pi^{*}$ transition of aromatic C-C bands and the $n-\Pi^{*}$ transition of $\mathrm{C}=\mathrm{O}$ bond respectively. As shown in Fig. 3, the UV-vis absorption spectra of RGO and $\mathrm{ZnO}$ are almost similar in the whole spectral region. The presently synthesized $\mathrm{RGO} / \mathrm{ZnO}$ nanocomposite exhibits three strong absorption peaks at 378,385 , and $420 \mathrm{~nm}$, with $\mathrm{Ph} \sim 6$, but not appear in the case of $\mathrm{pH} \sim 9$, and 12 which means absorption characteristics of $\mathrm{RGO} / \mathrm{ZnO}$ hybrid depends on $\mathrm{pH}$ value.

It is also found that absorbance increase with alkaline solution (in case of $\mathrm{Ph} 6$, and $\mathrm{Ph} 12$ (but decrease in the case of $\mathrm{Ph} \sim 9$ ) which concomitant increase in $\mathrm{SP}^{2}$. It is also clear from the Fig. 1 that absorption is shifted towards lower wavelengths which indicates strong coupling between RGO and semiconductor Nanoparticle [10]-[11].

\section{B. Photoluminescence Spectra of $\mathrm{RGO/ZnO}$ Nanocomposite}

It is immediately clear that in contrast to the broad absorbance features, PL peak is relatively centered on 400 nm.

The excitation features are readily observable between excitation wavelengths of 340 to and $450 \mathrm{~nm}$ (3.6-2.7.eV) which represent the absorbance energies corresponding to emission of blue-yellow light and yellow-green extinction wavelengths between (450-700nm). The Photo Luminescence indicates peaks of reducing intensities at increasing wavelengths of $452 \mathrm{~nm}, 470 \mathrm{~nm}$ and $493 \mathrm{~nm}$. These peaks are not as sharp as comparison to yellow peak emission, which can be attributed to oxygen vacancies and serves as a probe to monitor the interfacial electron transfer processes $[2]$.

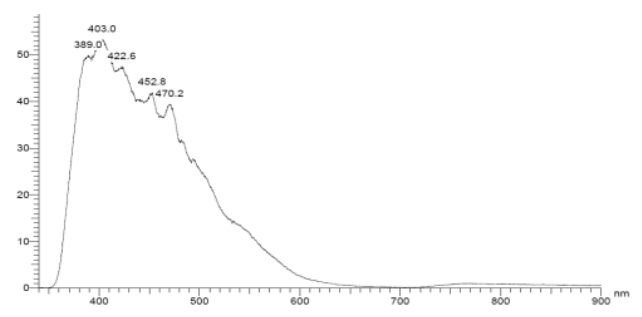

(a)

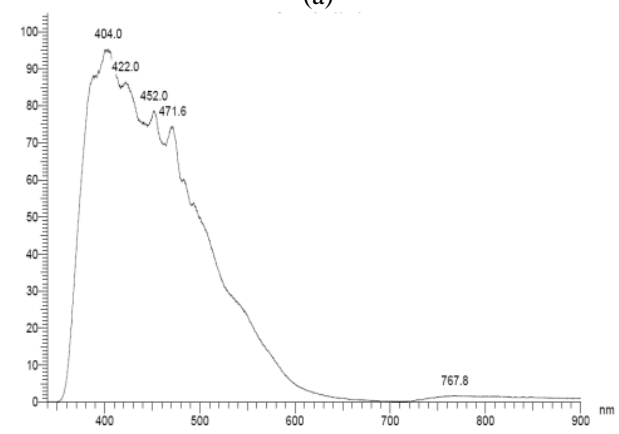

(b)

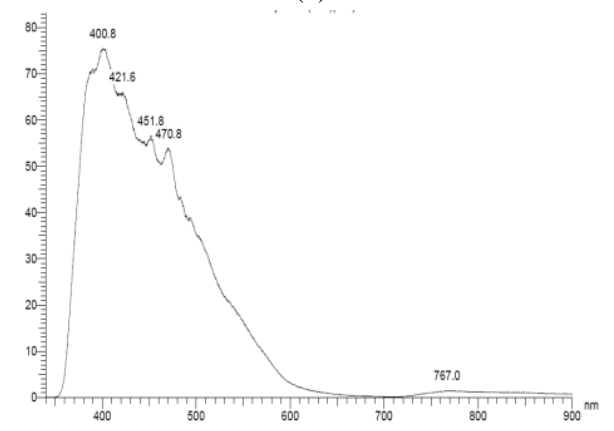

(c) 


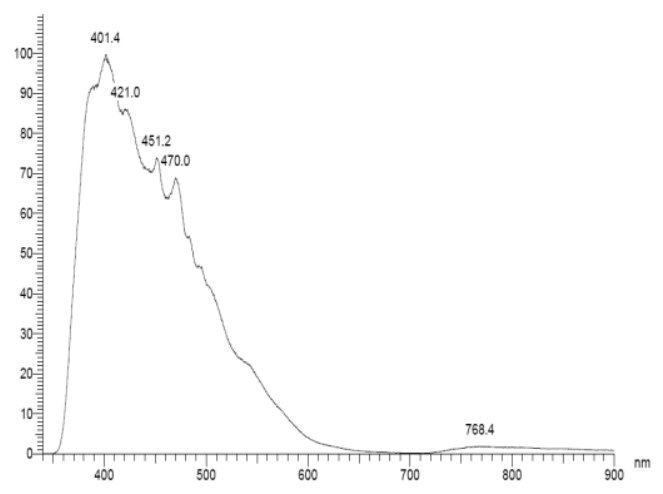

(d)

Fig. 2. (a) Photoluminescence spectra of $0.03 \mathrm{mg} / \mathrm{ml}$ RGO; (b) Photoluminescence spectra of $0.03 \mathrm{mg} / \mathrm{ml}$ RGO with $0.05 \mathrm{MZnO} \mathrm{Ph} 6$; (c) Photoluminescence spectra of $0.05 \mathrm{mg} / \mathrm{ml}$ RGO with $0.05 \mathrm{MZnO} \mathrm{Ph} \sim 9$; (d) Photoluminescence spectra of $0.01 \mathrm{mg} / \mathrm{ml}$ RGO with $0.05 \mathrm{MZnO} \mathrm{Ph} 12$.

The general features of the PL excitation spectra and their dependence of the degree of reduction are different from the red-IR emission as reported in previous studies [12], [13]. We have also observed weak red-IR emission at extinction wavelength $768.4 \mathrm{~nm}$ in $\mathrm{RGO}, \mathrm{RGO} / \mathrm{ZnO}$ at different $\mathrm{pH}$ and plotted graph between each excitation wavelength with corresponding intensity as shown in Fig. 3. In this graph the excitation intensity is observed to decrease with increase in wavelength and the sample of $\mathrm{Ph}$ value 12 , is observed to have highest excitation intensity.

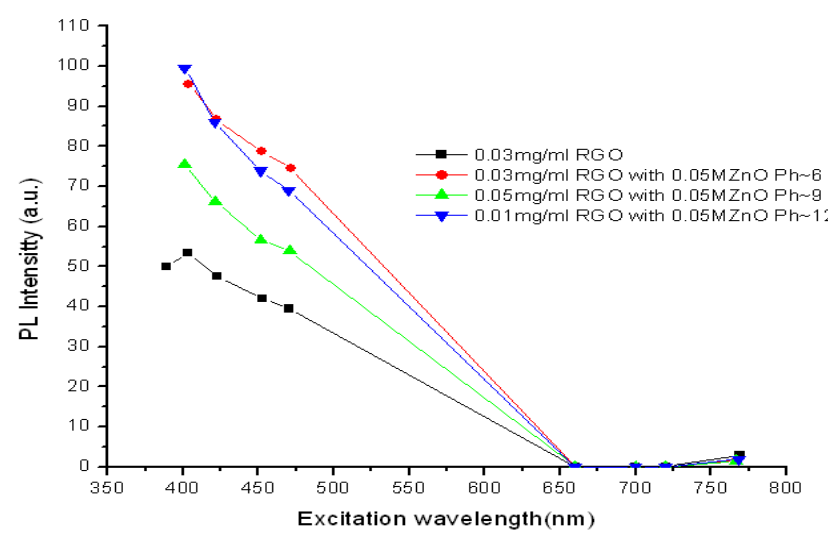

Fig. 3. The Excitation spectra RGO, RGO/ZnO were obtained for different wavelengths at different peak, of the emission spectrum ranging from 389 to $768.4 \mathrm{~nm}$.

\section{CONCLUSIONS}

Graphene oxide is often referred to as a disordered material [14]. The present study indicates that the $\mathrm{ZnO}$ nano particles have strong bonding with $\mathrm{GO}$ and forms stable composite material. $\mathrm{ZnO}$ acts as a probe and punches out electrons from GO lattice, thereby generating hole- electron pairs, contributing to special electronic properties. The variation in casting process can tailor the band gap as well. The nanocomposite so developed in the present study also indicates excitations in broad band frequencies indicating higher absorbance efficiency. It can be concluded that the inherent disorders of $\mathrm{GO}$, induced by the presence of $\mathrm{ZnO}$ functional groups, provides opportunities for tailoring its optoelectronic properties. $\mathrm{RGO} / \mathrm{ZnO}$ nanocomposite can further be prepared to contribute in improving the conductivity of transparent electrode material; controlling band structure and electron acceptor material and controlling and improving the functionalization and compatibility with other materials as interface layer material.

\section{ACKNOWLEDGEMENT}

The present study has been carried out at school of Nanotechnology of Rajeev Gandhi Technical University and we are grateful to the academic staff in supporting and university for facilitating us for experimental work. Our special thanks to the research lab of IISER Bhopal for providing us the characterisation facilities.

\section{REFERENCES}

[1] A. K. Geim and K. S. Novoselov, "The rise of Graphene," Nat. Materials, vol. 6, pp. 183, March 2007.

[2] A. Reina, X. Jia, J. Ho, D. Nezich, H. Son, V. Bulovic, M. S. Dresselhaus, and J. Kong, "Large Area Few layer Graphene films on Arbitrary Substrate by Chemical Vapor Deposition," Nano Lett., vol. 9 , pp. 30, 2009

[3] L. J. Cote, F. Kim, and J. X. Huang, "Langmuir-Blodgett Assembly of Graphene Oxide single layer," J. Am.Ch.m.Soc., vol. 131, pp. 1043, 2009.

[4] A. Lerf, H. He, M. Forster, and J. Klinowski, J. Phys. Chem., vol. 102, no. 23, pp. 4477-4482, 1998.

[5] Y.-W. Zhu, S. Murali, W.-W. Cai, X.-S. Li, J. W. Suk, J. R. Potts, and R. S. Ruoff, "Graphene and Graphene Oxide: Synthesis, Properties, and Applications," Ad-vanced Materials, vol. 22, pp. 3906, 2010.

[6] Kian, P. Loh, Q.-L. Bao, G. Eda, and M. Chhowalla, "Graphene oxide as chemically tunable platform for optical application," Nature Chem. vol. 2, December 2010.

[7] A. Bagri, C. M. M. Acik, Y. J. Chubal, M. Chhowalla, and V. B. Shenoy, "Structure evolution during the reduction of chemically derived graphene oxide," Natur Chem, vol. 2, pp. 581-587, January 2010.

[8] G. Williams and P. V. Kamat, Graphene Semiconductor Nanocomposite s:excited-state interaction $\mathrm{ZnO}$ nanoparticles and Graphene Oxide Langmuir, vol. 25, no. 24, pp. 13869, December 2009.

[9] W. S. Hummers and R. E. Offeman, "Preperation of Graphene Oxide," Chem. Soc., vol. 80, pp. 1339, March 1958.

[10] S. Stankovich, R. D. Piner, X. Chen, N. Wu, S. T. Nguyen, and R. S. Ruoff, J. Mater. Chem, vol. 16, no. 2, pp. 155-158, 2006.

[11] S. Gilje, S. Han, M. Wang, K. L. Wang, and R. B. Kaner, Nano Lett. vol. 7, no. 11, pp. 3394-3398, 2007.

[12] X. Sun, Z. Liu, K. Welsher, J. T. Robinson, A. Goodwin, S. Zaric, H. Dai, Nano Res., vol. 1, pp. 203, 2008.

[13] Z. Liu, J. T. Robinson, X. Sun, and H. Dai, "PEGylated Nanographene Oxide for Delivery of Water-Insoluble Cancer Drugs," Am. Chem. Soc., vol. 130, pp. 10876, 2008

[14] L. Zhengtang, M. V. Patrick, J. M. Eugene, A. T. C. Johnson, and M. K. James, Appl. Phys. Lett., vol. 94, pp. 111909, 2009.

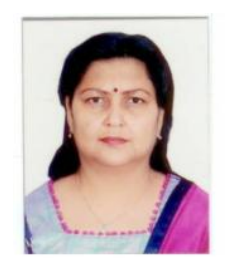

Purnima Swarup was born on 3rd September 1964, in Jabalpur, India. She has done Masters Degree in Physics in 1985 and completed Ph. D. in Energy Environmental Modeling in year 2000 from Bhopal University, M.P. - India.

She is presently professor and head of the Physics Department at Rajeev Gandhi Technical University of Government of M. P. Bhopal India. She is an academician \& researcher with twenty seven years of experience and completed many projects in her area of research interests. There are more than fifty peer reviewed research papers and four subjective books published to her credit. The two major popular books she authored worth mentioning are titled 'Engineering Physics - Fundamentals and Modern Applications' Published by 'Infinity Science Press LLC Hingham (Boston), Massachusetts' in April 2007 and a text book on environmental studies for engineering graduate course 'Energy Ecology Environment \& Society' Published in year 2002. Her major fields of study were particle physics, energy environmental modeling, renewable energy systems, fuel cells, global warming \& climate change, presently she is pursuing research in material science and nanotechnology. 